\title{
The Hands that Heal must not Bleed: Recommendations to Curb the Violence against Healthcare Workers in India
}

\author{
Amrit Mishra ${ }^{1}{ }^{\circ}$, Abhijit $V$ Boratne $^{2} \odot$, Balachandra V Adkoli ${ }^{3}$
}

\begin{abstract}
The life of a healthcare worker is full of challenges, both personally and professionally. Coronavirus disease-2019 (COVID-19) pandemic has only managed to burn them out even further. Amidst a period of uncertainty in India, a raging concern is the rise in violence against the healthcare workers. Despite great personal sacrifices made by them during this pandemic, the healthcare workers are disrespected, not paid enough and also get denied of a dignified life. If this trend continues, their morale would hit rock bottom. The day is not far when these conditions will force all the healthcare workers to boycott their services. This narrative review aims to throw light on the violent attitudes toward the healthcare workers and the recommendations to safeguard them, so that they can continue to serve the public in peace and with zeal.
\end{abstract}

Keywords: COVID-19, Crime, Government, Healthcare costs, Hospital, Recommendations, Violence.

SBV Journal of Basic, Clinical and Applied Health Science (2021): 10.5005/jp-journals-10082-03128

\section{INTRODUCTION}

Workplace violence is a global phenomenon, and it is seen many folds in healthcare institutions. It ranges from verbal abuse to mental torture, physical assault, and even sexual or racial harassment. However, increase in the number of violence against healthcare workers is evident during coronavirus disease-2019 (COVID-19) pandemic. At present, the medical professionals are being labeled as "professional looters" by the public due to the high out-of-pocket expenditure borne by patients. ${ }^{1}$

As the waves of COVID-19 thrashed the country, the healthcare workers are overburdened. Despite great personal sacrifices made by them, they face unexpected situations in their personal lives. For instance, the landlords have evicted out the healthcare workers and their families from their rented premises since the COVID-19 pandemic began. ${ }^{2}$

Many healthcare workers have faced the wrath of the public, police, and politicians. The violence has escalated to a point where the healthcare workers have incurred life-threatening injuries. The loss of their lives due to COVID-19 pandemic has added fuel to the fire. If this trend continues, the Indian doctors may get burnt-out and boycott their services. It is high time that the government takes drastic measures to curb violence against healthcare workers. ${ }^{3}$

\section{Why the Violent Attitude toward Healthcare Workers?}

\section{Acute Shortage of Manpower}

India has a shortfall of healthcare workers in primary health centers and other government health setups. Many times, the posts sanctioned lie vacant because of long bureaucratic procedures involved in recruitment. The shortage not only affects the quality of services, but also results in delay in accessing services, adding on to the frustration and anger of the public. Though medical colleges in India produce more than 67,000 medical graduates (MBBS) every year, the total number of postgraduate seats available is around 35,000 (MD/MS/DNB) only. A quote has also been passed down the generation of doctors that "There is no life
1,2Department of Community Medicine, Mahatma Gandhi Medical College and Research Institute (A Unit of Sri Balaji Vidyapeeth Deemed to be University), Puducherry, India

${ }^{3}$ Department of Medical Education, Centre for Health Professions Education (A Unit of Sri Balaji Vidyapeeth Deemed to be University), Puducherry, India

Corresponding Author: Amrit Mishra, Department of Community Medicine, Mahatma Gandhi Medical College and Research Institute (A Unit of Sri Balaji Vidyapeeth Deemed to be University), Puducherry, India, Phone: +91 9487738287, e-mail: amritmishra92@gmail.com

How to cite this article: Mishra A, Boratne AV, Adkoli BV. The Hands that Heal must not Bleed: Recommendations to Curb the Violence against Healthcare Workers in India. J Basic Clin Appl Health Sci 2021;4(4):81-86.

Source of support: Nil

Conflict of interest: None

for MBBS doctors without a postgraduation degree." As a result, many doctors sit home and prepare for postgraduate entrance examinations rather than offer service as medical officers. This every increasing backlog further impacts the doctor/patient ratio negatively. ${ }^{4}$

\section{Healthcare Workers Training Issues}

One of the major deficiencies identified in the medical curriculum is that less importance is given to honing the communication and interpersonal skills, which is most vital for maintaining doctor/ patient relationship. The students neither get training in these skills properly nor do they have a supervised practical environment to utilize them. Other essential skills that are left out are the ways to deal with difficult patients, and empathize with the distressed patients and their attenders, time, stress, and conflict management. In the current era, handling the media, sensitization on cultural sensitivity, crowd management, and treating VIPs without affecting normal services are assumed as much importance as disaster management skills. ${ }^{5}$ 


\section{Workplace-related Issues}

The casualty wards and emergency services of most hospitals are usually packed with patients and their attenders (family members, friends, and relatives). These are the primary zones of violent altercations. The sole reason for it is that the number of doctors attending emergency cases and the number patients needing urgent attention tend to remain disproportionate. Added factors, like the hassles during bringing the patients to the casualty service, the subsequent long waiting hours in admission, delay in referrals, inadequate communication, and lag in completing documentation formalities, especially in medicolegal cases lead to the patient attenders losing their patience. With the exception of few centers, the emergency services available in India are grossly inadequate. Poor infrastructural facilities, combined with weak human resource management, also play a role in the setback. ${ }^{4}$

\section{Patient-related Issues}

If we have a look at the reports of violence and the profile of assaulters, it can be seen that the culprits are usually the patient attenders, unrelated sympathizers, social media influencers, criminals, police, and even politicians, who are well connected. It is also possible to imagine their frustrations, leading to violent acts by those belonging to the poor socioeconomic status of the society, in the background of the ever-rising cost of medical treatment, lack of insurance cover, poor communication, and lack of awareness about health-related issues. ${ }^{6}$

\section{Role of Media}

Medical errors, though uncommon, can occur at the most unprecedented times. The patients may succumb to their illness despite appropriate medical care. But the public media, the press, the TV, and the newspapers are tempted to exaggerate the news throwing the medical field in a bad light. Recently, social media has emerged as a super powerful instrument to propagate one-sided opinions to garner public attention. ${ }^{4}$

The information gateway can be potentially dangerous if not handled in a responsible manner. Other causes of perceived lack of professionalism among healthcare workers include growing commercialization, nexus between doctors and pharmaceutical industry, and increased litigation due to growing consumer awareness and stiff competition from other systems of medicine. ${ }^{4}$

\section{An Insight of Postviolence Reaction}

According to an online survey of healthcare workers in Maharashtra by Centre for Enquiry into Health and Allied Themes (CEHAT), it is observed that most of them did not press charges against the violence and rather chose to suffer in silence. The reasons cited for this were that there would be no use to report such an incident, or there were no legal procedures in place and that it would only make matters worse for them. It was also found that the hospital administration took no action in that context and several healthcare workers were even blamed on top of that. Only a mere third of the hospitals recorded a medicolegal case in such incidents. ${ }^{7}$

\section{How to Identify the Warning Signs of Violence?}

Healthcare workers need to be alert of any kind of confrontation that could turn into violent behavior. For starters, it is recommended to use the Staring, Tone, Anxiety, Mumbling, and Pacing (STAMP) approach that indicates the early warning signs of violence. The STAMP approach consists of the following: ${ }^{6}$

- Staring:Threatening the healthcare workers for getting quicker response.

- Tone and volume of voice: Raising voice, yelling, and making sarcastic responses.

- Anxiety: Expression of worry, concern, and nervousness, especially in the emergency department.

- Mumbling: Incoherent, faltered response.

- Pacing: Showing restlessness and agitation. ${ }^{6}$

\section{Steps Taken by the Government So Far}

In 2019, the Health Ministry, Government of India, drafted the "Prohibition of Violence and Damage to Property Bill" for curbing violence against healthcare workers. But the Home Ministry of India dismissed it, quoting that there is no requirement for a separate law for a specific profession. ${ }^{7}$ This analogy is not justified as the healthcare workers face workplace violence many fold than other professionals.

This is where we have to take lessons from other countries. In the USA, the Occupational Safety and Health Act of 1970 (OSH Act) mandates that the employers must be responsible to provide their workers with a safe workplace free from hazards, death, or serious physical harm. As part of the OSH Act, the Occupational Health and Safety Administration (OSHA) was also set up to ensure safe and healthful working conditions. OSHA has laid down guidelines for identification of risk factors for violence in workplace settings. The USA Government took it one notch further with the introduction of the workplace violence prevention for healthcare and social service workers bill (violence prevention bill). This bill directs OSHA to issue health standards for the concerned employers within the healthcare and social service industries, to plan a comprehensive standard operating procedure (SOP) for preventing workplace violence. Other countries, like UK and Canada, have similar security for their healthcare workers. ${ }^{8}$ In line with global policy advancements, the Government of India should also focus on implementing similar measures.

The Epidemic Diseases Amendment Bill (2020) has given a new hope to the healthcare workers. It seeks to ensure that the violent offences against healthcare workers indulged in COVID-19 management are treated as nonbailable offences. It has a provision that the offender would be presumed to be guilty of the offence unless proved otherwise. This bill will put the commission or abetment of such violence to be punishable with imprisonment for a term of 3 months to 5 years and with a fine of ₹50,000-₹2,00,000. In case of causing grievous hurt, the imprisonment shall be from anywhere between 6 months and 7 years and with a fine of ₹1-5 lakh. The offences shall be investigated by an officer not below the rank of inspector within a period of 30 days, and trial has to be completed within 1 year. ${ }^{9}$

On May 3, 2021, the government announced the postponement of NEET-PG competitive entrance examination for at least 4 months in view of COVID-19 pandemic. But, this move only delays the admission of new postgraduates and further increases the burden on the existing healthcare workers. ${ }^{10}$

The existing agencies, their laws, and Indian Penal Code (IPC) sections pertaining to the protection of healthcare workers have been shown in Tables 1 and 2.,9,11-14 
The Hands that Heal must not Bleed

Table 1: Existing agencies and their laws in favor of protecting healthcare workers

\begin{tabular}{|c|c|c|c|}
\hline SI. No. & Name & Year initiated & What it does \\
\hline \multicolumn{4}{|c|}{ Government of India } \\
\hline 1 & Disaster Management Act & 2005 & $\begin{array}{l}\text { A section of this act condemns and punishes the liabilities (both civil and } \\
\text { criminal) for those violating its provision }\end{array}$ \\
\hline 2 & $\begin{array}{l}\text { State Specific Law: } \\
\text { Protection of Medicare Service } \\
\text { Personnel and Medicare Service } \\
\text { Institutions Act (a.k.a Medical } \\
\text { Protection Act) }\end{array}$ & 2008 & $\begin{array}{l}\text { Existing in } 19 \text { states of India, it caters to healthcare workers affiliated to } \\
\text { institutions and private practitioners for voicing against attacks on them and } \\
\text { damage to their property }\end{array}$ \\
\hline 3 & $\begin{array}{l}\text { Sexual Harassment of Women at } \\
\text { Workplace (Prevention, Prohibition, } \\
\text { and Redressal) Act (a.k.a POSH Act) }\end{array}$ & 2013 & $\begin{array}{l}\text { Endorses safe workplace as a woman's legal right and considers all forms of } \\
\text { sexual harassment at workplace as illegal }\end{array}$ \\
\hline 4 & $\begin{array}{l}\text { Epidemic Diseases (Amendment) } \\
\text { Bill }\end{array}$ & 2020 & $\begin{array}{l}\text { Seeks to make the incidents of violence on health workers treating COVID-19 } \\
\text { patients as a nonbailable offence }\end{array}$ \\
\hline \multicolumn{4}{|c|}{ NMC (erstwhile Medical Council of India) } \\
\hline 1 & $\begin{array}{l}\text { (Professional Conduct, Etiquette, } \\
\text { and Ethics) Regulations }\end{array}$ & 2002 & Guidelines for ethical conduct of healthcare workers \\
\hline \multicolumn{4}{|c|}{ Voluntary organizations that voice out for healthcare workers } \\
\hline 1 & $\begin{array}{l}\text { IMA (erstwhile All India Medical } \\
\text { Association) }\end{array}$ & 1928 & $\begin{array}{l}\text { Registered under the Societies Act of India, it is a society that caters to the } \\
\text { interest of doctors or the well-being of the community at large }\end{array}$ \\
\hline 2 & $\begin{array}{l}\text { Centre for Enquiry Into Health and } \\
\text { Allied Themes (CEHAT) }\end{array}$ & & $\begin{array}{l}\text { Exists for the well-being of the disadvantaged masses, for strengthening } \\
\text { people's health movements and for realizing right to health and healthcare }\end{array}$ \\
\hline 3 & Medicos Legal Action Group & 2012 & $\begin{array}{l}\text { A nonprofit organization at Chandigarh for doctors seeking to pursue legal } \\
\text { actions against professional, training, and workplace policies and incidents }\end{array}$ \\
\hline
\end{tabular}

Table 2: Existing IPC sections in favor of protecting healthcare workers

1 Applicable to only government service healthcare workers

a Section 186 For obstructing public servant in discharge of a public function

b Section 332 Voluntarily intending to hurt to deter public servant from discharge of his duty

c Section 353 Assault and criminal force to deter public servant from discharge of his duty

2 Applicable to all healthcare workers (including private practitioners)

a Section 34

Criminal acts done by several persons with common intention

b Section 120 120B-Criminal conspiracy

c Section 143 Unlawful assembly

d Section 294 Punishment for obscene acts or words in public

e Section 307 Attempt to murder

f Section 319 Hurt

g Section 320 Grievous hurt

h Section 323 Voluntarily causing hurt

i Section 342 Wrongful confinement

j Section 425 Causing damage to property

k Section 447 Criminal trespassing

I Section 506 Punishment for criminal intimidation

\section{Voice of the Indian Medical Association}

Even with all the above laws in place, the violence against doctors doesn't seem to curb down. Pointing to the increasing violent attitude against healthcare workers, the Indian Medical Association (IMA) has urged the government to enact a central law with nonbailable IPC and Code of Criminal Procedure (CrPC) sections and also for appointing officers for investigation and deciding punishment against the culprits. The justification provided by the association is that the control of such violence is not feasible unless the legal action is associated with IPC and the CrPC sections specific for the profession. Without such specific provisions, it is difficult for the victimized healthcare workers to lodge a complaint as well as the police to register such complaints. ${ }^{8}$ More often than not, the healthcare workers fail to secure justice and the perpetrators roam scot-free.

The association has also demanded that the hospitals should be declared as a protected zone with mandatory police security. The IMA in its study found that over $75 \%$ of doctors across the country faced some sort of violent altercation and that $68.33 \%$ of it was committed by the patient's attenders. The association criticized that amidst the mounting pandemic crisis and shortage of resources, when a patient is on the verge of death, the attenders show their anger and frustration by attacking hospital property and healthcare workers. ${ }^{8}$

The IMA also claims that the healthcare workers tend to sympathize with the situation of the patient. As a result, they avoid reporting the violence and are forced to seek the help of law only when they face a direct threat of life. The association has demanded that the entire healthcare administration should be revamped with a cadre of Indian Medical Service (IMS), who shall be well versed with the technical and administrative skills required for effective execution of healthcare justice and administration. ${ }^{15}$

\section{Recommendations to Curb the Violence against Healthcare Workers}

With the rise in mob violence incidents, healthcare workers are becoming skeptical and reluctant to take up seriously ill 
cases fearing public violence. Unfortunately, such an attitude compromises healthcare and defeats the very purpose of the healthcare delivery system. Unless a drastic change is made to ensure that the hospital environment is free violence, the healthcare workers won't be able to work to their maximum potential. ${ }^{6}$

The recommendations to curb the violence against healthcare workers require participation and working of several stakeholders as shown in Flowchart 1.

\section{Role of Medical Education}

Medical education endorses the integration of the head (cognitive skills), the hands (psychomotor skills), and the heart (empathy skills). Yet, in our country, the emphasis has largely been on the head, barely the hands, and almost not at all on the heart. As a result, the Indian medical graduates are found lacking in empathic communication. ${ }^{7}$ The step taken by the National Medical Council (NMC) in revising the curriculum of MBBS is laudable. The revised curriculum based on competency-based medical education involves a foundation course during the first year, a longitudinal thread of "Attitude, Ethics and Communication" (AETCOM) with defined competencies and emphasis on formative assessment where soft skills can be developed in a graded manner. ${ }^{16}$

However, the implementation of AETCOM is still budding. It needs to be adequately monitored to ensure that it is optimally utilized and has a positive impact on medical education. The program needs to be standardized, and it needs to include the sociopolitical factors involving patients and their attenders, address issues, such as treating victims of sexual abuse or attempting to understand the unique challenges faced by members of the LGBTQIA+ community, and techniques for nonviolent crisis prevention, and to deal with the grief of the patient's attendants. The provision of foundation course is a golden opportunity to sensitize the fresh medical students to the real-time incidents faced by their mentors. ${ }^{17}$ We can consider having 1 day of every department's clinical posting exclusively for imparting medical education training. This would involve the students to interact with the department's staffs and learn about the extra-academic experiences and notable events that happen during their service.

\section{Role of the Institutional Administration}

Effective management of human resources in the institutes can reduce the burden of the healthcare workers and prevent the

Flowchart 1: Recommendations to curb the violence against healthcare workers

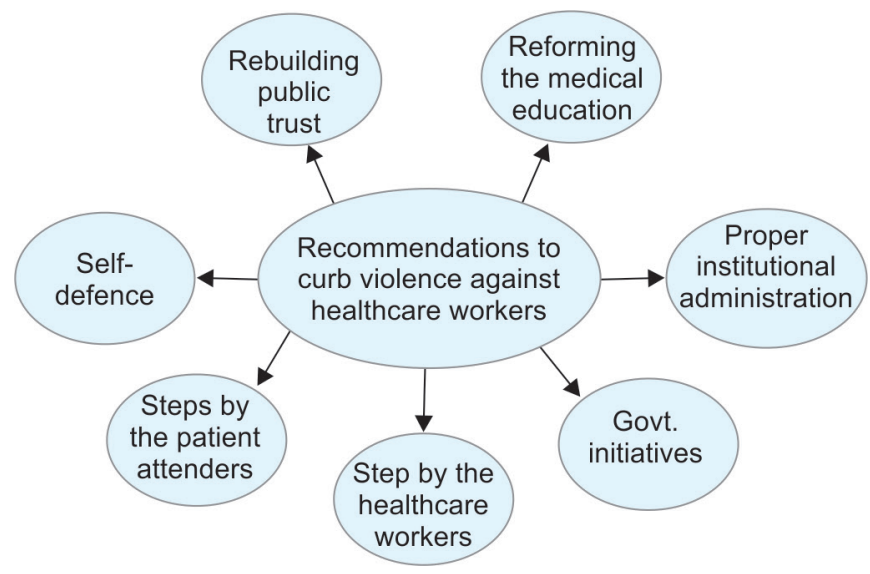

chances of violent altercations. An SOP should be made and followed strictly. In foreign countries, the practice of "Code Purple" is quite common. It involves measures to be taken in case of violence in a healthcare setting. The security staffs have to respond and assist immediately. All staff (except operation theatre and ICU) would form a human chain to safeguard the healthcare worker in danger. Closed-circuit television monitoring in sensitive areas, like the casualty wards, is must and should be placed. ${ }^{6}$ Applying "Code Purple" in Indian scenario can help mitigate the acts of violence. An alarm system akin to fire alarm can be introduced. The hospitals can collaborate with software-developing organizations and have a violence control application developed, which can be installed by every employee in their mobile phones. This can come in handy to act instantly. 6

A live digital board displaying the availability of beds in the casualty wards and the intensive care units (ICUs) should be placed at the entrance of the hospital to enable the attenders to be ready to transfer the patient to another hospital after first aid. The prehospital staff should work hand in hand with the casualty staff. ${ }^{4}$

\section{Steps to be Taken by the Government}

The government must bear accountability and responsibility for the safety of healthcare workers. The measures taken by the government need to be examined for effective implementation. Many policies may end up just as paper work, unless followed up diligently. An increase in the government's budget on healthcare and increasing insurance penetrance is a much-talked move. This would bring down the burden of treatment cost of the patient. Reconsideration of approving the "Prohibition of Violence and Damage to Property Bill," 2019, and framing sections of the IPC and $\mathrm{CrPC}$ for punishing the violent perpetrators are the need of the hour. ${ }^{18}$

India faces severe shortage of healthcare workers. The NMC's goal of bringing the doctor/patient ratio to 1:1000 by 2031 is a farfetched dream at the moment. It cannot be accomplished without the government addressing the need to increase healthcare institutions and its postgraduation seats. At the same time, it must also be ensured that quality of services is not compromised. ${ }^{7}$

As per the World Health Organization's resolution on May 28,2021 , the member nations need to invest in the healthcare workforce and ensure that they are skilled, trained, equipped, supported, and enabled to carry their intended work. The need of decent pay, appreciation, a safe working environment, and protection of their rights were deemed necessary. Our Health Ministry must try to implement the above measures at the earliest. ${ }^{19}$

As this pandemic has created quite a big impact, the Government of India can publish a special edition document on the COVID-19 pandemic period, highlighting experiences and issues of the public and private institutions, the frontline workers and patients, and strategies to overcome them. This can be disseminated to healthcare institutions all over the country and can also be used as guidelines for future reference.

\section{Steps to be Taken by the Healthcare Workers}

The ultimate onus of the healthcare workers safety lies on them. The healthcare workers should take due precautions while facing patient attenders. Taking time to communicate with the attender about the patient's health condition and prognosis properly and preferably in the native language is the first step. Getting a valid and informed consent, preferably in audio/visual mode, is the next step. Proper documentation has to be done, and it must be 
countersigned by the attenders asserting that they understand the situation of the patient. ${ }^{9}$ In the event of suspecting any danger, the healthcare workers must be prepared to save themselves. Keeping the violence control mobile application turned on all the time whether on or off duty and being aware of the safe places within the campus can be very useful if violent situations arise.

\section{Steps to be Taken by the Patient Attenders}

The patients and their attenders have equal responsibility in preventing and resolving conflicts. They should be aware of the patient's health condition. They should accept that healthcare workers are not magicians and that everyone cannot be saved. Doctors cannot be held responsible for every death occurring in the hospital. Deaths can happen due to variety of factors, such as accidents, unhealthy lifestyle, and associated comorbidity and inadequate compliance of medical prescriptions. They should have discussion with their treating doctor about the available treatment options, the reason for the tests conducted, the cost of each treatment, and instructions for follow-up. They should be in touch with the institute's counselor and also be up-to-date with the patient's condition. If not satisfied with a doctor, they can always consult for a second opinion and take an appropriate decision whether to continue treatment or not. ${ }^{17}$

\section{Role of Media in Rebuilding the Trust of the Public}

The media has a great responsibility in giving appropriate facts to the people in right time and in right manner. They should avoid exaggerating the news for increasing their popularity and rather put forward the unbiased news regarding the medical conditions as well as the action taken by the health workers. The media should portray on the functioning of hospitals, the daily challenges faced by healthcare workers, the desired etiquette of citizens in a hospital, and the kind of punishment which would apply to violent perpetrators. This would help in making the patients and their attenders more empathic toward the healthcare workers. ${ }^{7}$

\section{Novel Ways to Protect the Healthcare Workers from Violence}

The Government of Maharashtra is planning to implement selfdefense as a part of the school curriculum after an online petition filed by a women's self-defense coach from Pune about the same. ${ }^{20}$ Self-defense training can also help students to develop:

- Physical fitness

- Self-discipline

- Self-confidence

- Awareness about the various crimes and

- The skills needed to defend oneself from such situations

Addition of such self-defense skills in the curriculum of healthcare institutions will not only reduce the incidence of attacks against doctors but also empower them to assert themselves that they are their own savior. Furthermore, it can also create work opportunities for the self-defense coaches. ${ }^{21}$

In 2020, a USA-based institute, CoxHealth, has tried and tested the usage of panic buttons with their healthcare employees. The panic buttons are the size of a passport size photograph and can be embedded on the employees' nametags. When the button is pressed, a trigger alert with the employee's location is sent to the public safety officers. A survey among the employees found that the buttons created a sense of security. ${ }^{22}$ This technology can be utilized by the healthcare workers in the Indian scenario for instantly conveying the violent incidents.

\section{Implications of the ReView}

This narrative review presents the parameters related to workplace violence against healthcare workers. It has been speculated that the number of healthcare workers who may have suffered from workplace violence in some form is more than the number of reported cases. An episode of violence altercation can have impacts on both short- and long-term basis for the healthcare workers. It will shatter their morale. Lack of safety protocols in emergency rooms and ICUs may exert added stress during decision making.

Furthermore, repeated episodes of violent altercations, especially leading to grievous injuries, may deter the potential candidates away from specific clinical specialties. Hence, it is not enough to only prevent the violence, but the institution should provide a strong empathic and psychological support system to those who have faced such violence. This would be a good reassurance for them.

\section{Implications for Future Research}

Several risk factors and mitigating strategies have been given in this review. Further research can be advocated by taking into account of the violent instances, the associated patient statuses and profiles, the healthcare workers expectations for safety, the healthcare institutional structure and protocols, its social functioning, and trials of novel violence mitigation strategies. Furthermore, research must involve qualitative aspect with focus on individual healthcare workers' preferences. An in-depth research using these parameters would be helpful to identify the lacunae and frame strategies.

\section{Strengths and Limitations of the Review}

Several strategies have been advocated to curb workplace violence in the healthcare settings. A majority of these strategies have comprehensively focused on the rising importance of improvement of communication and interpersonal skills via AETCOM module, making positive changes in institutional and governmental policies and creating awareness in each stakeholder about their social responsibilities in a healthcare setting. Institutional specific characteristics, like patient load, patient profiles, availability of healthcare workers and the vacancies, funding, resources, infrastructure, and location of the institute, should be considered to determine how effectively these strategies can be incorporated.

While drawing the inferences, several limitations of this review must be kept in mind. Firstly, as this is a narrative review, it might fail to cover all relevant articles on the topic in discussion. The aim was to throw light on the violent attitudes toward the healthcare workers and the recommendations to safeguard them, especially with regard to diversity in situations. Secondly, we have associated the risk factors for violence against healthcare workers with the lack of resources and training, and the role played by the institutions, patients and attenders, and the public media. There may be additional factors that might have been missed. Thirdly, some recommendations have been presented, which are focused on individual, educational, institutional, public media, and governmental aspects. Other strategies which might be effective but not systematically studied or documented might have been missed out. 


\section{ConcLusion}

The need for providing adequate security to the doctors against the growing incidence of violence has been well established. We have argued that the problem has many aspects and the solution lies in a collective and coordinated action by the medical establishments, the healthcare personnel, patients, and civil society. Sporadic approach, such as tightening the laws or providing additional security force, may have marginal benefit, but not long-term benefits. A multipronged approach is the need of the hour. We need ongoing dialogue, introspection by each stakeholder, and mutual respect, which are the corner stones for building an effective healthcare delivery system. This requires leadership at all levels that can stimulate collective action, mutual trust, and personal commitment.

The life of a healthcare worker is filled with challenges from the point of start of their education. Though violence against them is on rise during the pandemic times, they continue to provide their service. The road to prosperity for our country can be reached only with its healthy population. But, this is possible only when the hands that save lives do not bleed.

\section{ORCID}

Amrit Mishra 은 https://orcid.org/0000-0003-0830-3084

Abhijit V Boratne ㄴ https://orcid.org/0000-0001-7698-303X

Balachandra V Adkoli @ https://orcid.org/0000-0002-4873-0307

\section{References}

1. Kumar NP, Betadur D, Chandermani. Study on mitigation of workplace violence in hospitals. Med J Armed Forces India 2020;76(3):298-302. DOI: 10.1016/j.mjafi.2019.09.003.

2. Kapila S. Doctors deserve dignity, security as they risk their lives during the pandemic. 2020. Available from: https://indianexpress. com/article/opinion/columns/coronavirus-lockdown-doctors-safetyhealthcare-workers-attacked-siddharth-kapila-6383707.

3. DeSouza G. Goa resident doctors threaten to withdraw services at Covid hospitals. 2021. Available from: https://www.hindustantimes. com/india-news/goa-resident-doctors-threaten-to-withdrawservices-at-covid-hospitals-101619765687180.html.

4. Priya K, Pathak VK. Violence against doctors: before and during the pandemic of COVID-19. Int J Community Med Public Health 2020;7(10):4189-4192. DOI: 10.18203/2394-6040.ijcmph20204394.

5. Parija SC, Adkoli BV. Effective medical communication: the A B C D E of it. 1st ed. Springer; 2020.

6. Dora SSK, Batool H, Nishu RI. Workplace violence against doctors in India: a traditional review. Cureus 2020;12(6):e8706. DOI: 10.7759/ cureus.8706.

7. Mehta D, Sharma R, Agarwal A, Shrivastava S. Violence against healthcare professionals in India: recent legal and policy issues. 2020. Available from: https://vidhilegalpolicy.in/wp-content/
uploads/2020/01/200131_Violence-against-HealthcareProfessionals-Recent-Legal-and-Policy-Issues.pdf.

8. Chattopadhyay S. IMA demands central law with IPC sections for violence against healthcare workers and hospitals. 2021. Available from: https://medicaldialogues.in/news/health/doctors/ ima-demands-central-law-with-ipc-sections-for-violence-againsthealthcare-workers-and-hospitals-77003.

9. NDTV. Parliament passes bill to protect healthcare workers against violence. 2020. Available from: https://www.ndtv.com/india-news/ parliament-passes-bill-to-protect-healthcare-workers-againstviolence-2299007.

10. Unnithan S. Covid second wave: why doctors are alarmed over attacks on medical staff. 2021. Available from: https://www.indiatoday.in/ india-today-insight/story/covid-second-wave-why-doctors-arealarmed-over-attacks-on-medical-staff-1798489-2021-05-03.

11. Aggarwal R. India needs an urgent law to protect all health workers from violence. 2020. Available from: https://thewire.in/health/indiahealth-workers-violence-protection.

12. Niveda Foundation. Prevention of sexual harassment - POSH law. 2013. Available from: $\mathrm{http}: / / w w w . n i v e d a f o u n d a t i o n . o r g / p r e v e n t i o n-$ of-sexual-harassment-posh-law.

13. Indian Medical Council. (Professional Conduct, Etiquette and Ethics) regulations. 2002. Available from: https://wbconsumers.gov.in/ writereaddata/ACT\%20\&\%20RULES/Relevant\%20Act\%20\&\%20 Rules/Code\%20of\%20Medical\%20Ethics\%20Regulations.pdf.

14. Medicos Legal Action Group. About MLAG. 2012. Available from: http://www.mlag.in/index.php/about.

15. Business Standard. Health ministry must wake up and respond to Covid-19 challenges: IMA. 2021. Available from: https://www. business-standard.com/article/current-affairs/health-ministry-mustwake-up-and-respond-to-covid-19-challenges-ima-121050801100_1. html.

16. Adkoli BV. Teaching professional values in medical education. Natl Med J India 2015;28(4):194-197. PMID: 27132730.

17. Medical Council of India. AETCOM module. 2018. Available from: https://www.mciindia.org/CMS/wp-content/uploads/2020/01/ AETCOM_book.pdf.

18. Kumar R, Roy P. Violent-acts against doctors and healthcare professionals in India: call for action. J Family Med Prim Care 2019;8(11):3457-3460. DOI: 10.4103/jfmpc.jfmpc_896_19.

19. World Health Organization. Update from the seventy-fourth World Health Assembly. 2021. Available from: https://www.who.int/news/ item/28-05-2021-update-from-the-seventy-fourth-world-healthassembly-28-may-2021.

20. India Today. Maharashtra government to include compulsory selfdefence classes in school curriculum. 2019. Available from: https:// www.indiatoday.in/education-today/news/story/maharashtragovernment-to-include-compulsory-self-defence-classes-in-schoolcurriculum-1457713-2019-02-16.

21. Nair S. Self defence: educational curriculum. 2018. Available from: https://medium.com/@sumitranair/self-defence-educationalcurriculum-974a5475946d.

22. Berger E. US hospitals outfitting nurses with panic buttons amid rise in assaults. 2021. Available from: https://www.theguardian.com/ us-news/2021/sep/30/hospitals-nurses-panic-buttons-to-security. 